\title{
The Relationship between Psychological Hardiness, Coping Strategies and Perceived Stress among Working Adults
}

\author{
Karishma. N. Nanavaty ${ }^{1}$, Vaishnavi Verma ${ }^{2}$, Archana Patki $^{3}$ \\ ${ }^{1}$ Postgraduate Student, Department of Psychology, Maniben M.P. Shah Women's College of Arts \& Commerce, \\ Matunga, Mumbai. \\ ${ }^{2}$ Assistant Professor, Department of Psychology, Maniben M.P. Shah Women's College of Arts \& Commerce, \\ Matunga, Mumbai. \\ ${ }^{3}$ Professor and Head, Department of Psychology, Maniben M.P. Shah Women's College of Arts \& Commerce, \\ Matunga, Mumbai. \\ E-mail - vaishnavi.verma1086@gmail.com
}

\begin{abstract}
Background: In this modern era, stress is an unavoidable aspect in everyday life which can have an adverse impact on one's psychological and physical well-being. The daily stress faced by full time employed working men and women has led to absenteeism, reduced productivity, and turnover. But it has been conceptualized that psychological hardiness and effective use of coping strategies could reduce the negative impact of stressors. This research predicted that there exist a relationship between hardiness, coping strategies and perceived stress among working adults.

Methodology: The study involved qualitative and exploratory design to know the relationship between Psychological Hardiness, Perceived Stress and Coping Strategies among working adults. For this research study, 100 working adults, consisting of 50 males and 50 females were emailed the selected instruments, The Hardiness Scale, The Ways of Coping Questionnaire and The Perceived Stress Scale. Along with these instruments, the consent form and the demographic data questionnaire was also emailed to the participants. These instruments and the forms were sent online and the responses were recorded automatically.

Results: A negative correlation was established between Perceived stress and Psychological Hardiness. A negative correlation was established between Perceived stress and Coping Strategies. A strong positive correlation between the predictor variables Hardiness and Coping Strategies was noted.

Conclusion: Coping Strategies did not help to predict how working adults perceived their level of stress. This could be because Coping Strategies could be ineffective in nature and such strategies could just help the individuals to rejuvenate themselves. There existed a strong positive correlation between Hardiness and Coping Strategies which is also consistent with the past studies.
\end{abstract}

Key Words: Hardiness, Coping Strategies, Perceived Stress, working adults.

(Paper received $-11^{\text {th }}$ May 2016, Peer review completed $-8^{\text {th }}$ August 2016, Accepted $-12^{\text {th }}$ August 2016)

\section{INTRODUCTION}

\section{Concept of Psychological Hardiness}

Psychological hardiness is a construct that was developed to describe an inner resource [1] or constellation of personality characteristics [2] associated with good health and optimal performance under conditions off high stress. Hardiness as defined as a personality trait consisting of three related general dispositions of commitment, control, and challenge that serve as a psychological resources in dealing with stressful 
situations. The control disposition was defined as a tendency to believe and act as if one can influence the events in one's life and control or effectively manage those events. Hardy individuals feel and believe as though they are influential, rather than feeling helpless, in facing the rewards and punishments of life. Psychologically hardy individuals tend to have an internal locus of control [3]. The commitment disposition was defined as a tendency to be actively involved and fully engaged in the activities in one's life and social environment. The challenge disposition was defined as the belief and acceptance that change is normal and presents opportunities for personal growth, rather than as a threat to their security. Hardiness is believed to be developed early in life and remain relatively stable over time [4]. Salvatore Maddi described hardiness as a pattern of attitudes and skills that provides the courage and strategies to turn stressful circumstances from potential disasters into growth opportunities instead. He also stated that hardiness requires the courage and motivation to face stressors accurately rather than to deny or catastrophize. Such courage will lead to active coping, problem solving, and the giving and receiving of social support [5]. Psychological hardiness that consists of commitment, control and challenge, affects how successfully one adapts and interacts within one's social environment, including the workplace [6]. Hardy individuals are more resistant to stress because they choose to face it. These individuals also tend to interpret stress as making their lives more interesting. For example, the hardy individual sees a conference meeting with a supervisor as an opportunity to persuade the supervisor, rather than as a risk to their position [7].

\section{Concept of Coping Strategies}

Since it is known that no individual can remain in a continuous state of tension, some strategy is always adopted by a person undergoing a great deal of stress. These strategies are called 'Coping Strategies' [8]. The coping activities are consciously directed behaviors intended to modify, and to eliminate symptoms. Folkman and Lazarus have defined coping as the constantly changing cognitive and behavioral efforts to manage the specific internal or external demands that are appraised as taxing or exceeding the resources of the person [9]. Coping can be defined as the cognitive and behavioural efforts that individuals make to manage situations appraised as potentially harmful or stressful [10]. According to Fleishman [11], coping could refer to either strategies or results. As a strategy, coping refers to the different methods that individuals employ to manage their specific circumstances, while coping as a result refers to the eventual outcomes of the chosen strategy for the individual. There are several components of the coping process. First, appraisals of the harm or loss posed by the stressor [12] are thought to be important determinants of coping. Second, appraisal of the degree of controllability of the stressor is a determinant of the coping strategies selected. A third component is the person's evaluation of the outcome of their coping efforts and their expectations for future success in coping with the stressor.

Lazarus and Folkman [9] have described two types of coping strategies used by individuals while facing any adverse situation. The two types of coping strategies are: Problem-Focused Coping \& EmotionalFocused Coping. In Problem-Focused Coping, the individual manages or alters the problem that is causing the distress. In Emotional-Focused Coping, the coping is directed at regulating emotional responses to the problem. An individual makes use of Emotional Focused forms of coping when nothing can be done to change or alter the harmful threatening situation.

\section{Concept of Stress}

Stress refers to an individual's reaction to a disturbing factor in the environment. It is an adaptive response to an external situation that results in physical, psychological, behavioral deviations for individuals. Stress arises when individuals perceive that they cannot adequately cope with the demands made on them or when they cannot cope with threats to their well- being [13]. One famous stress response called the "fight or flight" response was first developed to explain our bodily reaction to stress. The "fight or flight" response is our body's sympathetic nervous system reacting to a stressful event by producing endocrine hormones such as adrenaline and cortisol to heighten our response towards a perceived threat or challenge [14]. The body's responses include increased heart rate and blood pressure, increased skeletal muscle tension, and alertness [15]. Mason has identified three definitions of stress, namely viz. an internal state of the organism which is sometimes referred to as strain, an external event or stressor and an experience that arises from a transaction between a person and the environment [16]. 


\section{Theories of Stress}

The sociological theory of stress views stress as an interaction of an individual's position in the social organization that exposes them to various stressors, which in turn give rise to stress outcomes [17]. It looks into the problems rooted in social roles that often endure in an individual's relationships, experiences and wellbeing causing role strain. The theory also takes into account the convergent effects of significant life events and daily life hassles that reflect important life experiences that are sometimes stressful. Thus, the theory proposes to examine stressful experiences as a whole, in combination of various groups of stressors in the organization of lives and structure of experience to effectively analyse and pinpoint the stressors that causes durable strains [18]. The transactional model of stress and coping (TMS) contend that stress is subjective where individuals experience the same stressor differently [19].

\section{Occupational Stress}

In this fast-paced world, individuals at workplace are facing tremendous amount of stress. Occupational stress has many negative effects, such as impaired performance and effectiveness, reduction in productivity, health problems, absenteeism, turnover, alcohol and drug usage, deliberate destructive behaviours, e.g. spreading of rumours and stealing [20].

\section{Models of Occupational Stress}

Various models have been developed to understand occupational stress, such as the Person- Environment Fit Model [21] and the Demand-Control Model [22]. According to the person-environment fit model, there are two factors determine stress, namely, environmental demands and person's ability either real or perceived. Stress occurs when there is a mismatch between the environmental demands and the person's ability. The emotion felt by a conflict person is an important factor for stress when there are gaps between job expectations and employee's ability to meet the expectations. Stress also can result from task conflicts, for example ambiguous roles set by employers to employees. Task ambiguity also contributed to stress when employees are given inadequate instruction about their roles. Such conflicts may result in work dissatisfaction and may lead to unfavorable consequences on their work performance. In addition to the person-environment fit model and the demand-control model, a third theoretical concept is proposed to assess adverse health effects of stressful experience at work is the effort-reward imbalance model. The focus of this model is on reciprocity of exchange in occupational life where high-cost/low-gain conditions are considered particularly stressful [23].

It has been conceptualized that psychological hardiness and effective use of coping strategies could reduce the negative impact of stressors. This research predicted that there exist a relationship between hardiness, coping strategies and perceived stress among working adults.

\section{METHODOLOGY}

\section{Participants}

The population for this study included working adults who were employed on a full-time basis. The data for the study was collected from 100 working employees, consisting of 50 males and 50 females residing in Mumbai city and Delhi city. The age criterion of the participants was 25 to 35 years of age.

\section{Research Design}

The research design was quantitative in nature and it is explorative as it aimed to explore the relationship between psychological hardiness, coping strategies and perceived stress. For this research standardized questionnaires were used which have a likert scale

\section{Instrumentation}

For this research study, the data was collected by using a set of standardized instruments, which was easily administered and scored. 
1. The Hardiness Scale - It is a 12 item questionnre that measures the commitment, control and challenge components of hardiness. Scoring is done on a 4 point likert scale, ranging from $0=$ strongly disagree, $1=$ mildly disagree, $2=$ mildly agree, $3=$ strongly agree. The total of control score, commitment score and challenge score is obtained, which is then added up to obtain to total hardiness score. A total score that ranges from 10-18 indicates a hardy personality, 0-9 indicates a moderate hardy personality and below 0 indicates low hardiness [24].

2. The Ways of Coping Questionnaire (Revised) - It is a 66 item questionnaire and consists of 8 subscales that include a wide range of thoughts and actions that people use to deal with either their internal or external demands of specific stressful encounters. The scoring is based on a 4 point likert scale. The responses range from 0 to 3 with $0=$ does not apply or not used, $1=$ used somewhat, 2 = used quite a bit, and 3 = used a great deal. The following are the 8 subscales: Confrontation, Distancing, Self-controlling,Seeking social support, Accepting responsibility (or blame), Escape-avoidance, Planning and problem solving and Positive reappraisal [25].

3. Perceived Stress Scale - It is the most widely used psychological instrument for measuring the perception of stress. It is a measure of the degree to which events in one's life are appraised as stressful. The items are designed to know how unpredictable, uncontrollable and overloaded respondents find their lives. The scale includes 10 items. The questions in the scale ask about feelings and thoughts in the last month. Scoring is done on a 5 point likert scale. The response range from $0-4$, with $0=$ never $1=$ almost never, $2=$ sometimes, $3=$ fairly often and $4=$ very often [26].

\section{RESULTS}

A non- experimental, explorative study was conducted to determine the relationship Hardiness, Coping Strategies and Perceived stress among working adults. The number of participants were 100 working adults, which included 50 males and 50 females. The results of the findings are summarized below. Table 1 shows the descriptive statistics, which includes the mean and the standard deviation. The mean obtained for Perceived Stress was 18.44 and the standard deviation was 7.84. The mean obtained for Hardiness was 4.55 and the Standard deviation was 5.41.The mean obtained for coping strategies was 75.62 and the standard deviation was 11.66 .

Table 1 - Mean and the Standard Deviation of the Predictor variables( Hardiness and Coping Strategies) and the outcome variable (Perceived Stress)

\begin{tabular}{|l|r|c|}
\hline \multicolumn{2}{|c|}{ Mean } & Std. Deviation \\
\hline Perceived Stress & 8.44 & 7.847 \\
\hline Hardiness & 4.55 & 5.419 \\
\hline Coping Strategies & 75.62 & 11.667 \\
\hline
\end{tabular}

Table 2 shows the Pearson Product Moment Correlation coefficient between every pair of variables. There exist a negative correlation between Perceived stress and Psychological Hardiness $(\mathrm{R}=-0.82, \mathrm{P}>0.05)$ This shows that Psychological Hardiness does not help to predict the level of stress faced by working adults. A negative correlation can also be established between Perceived stress and Coping Strategies $(\mathrm{R}=$ - 0.54, $\mathrm{P}>0.05)$. This shows that Coping Strategies also does not help to predict the level of stress faced by working adults. Also it can be seen that there exist a strong positive correlation between the predictors, Hardiness and Coping Strategies $(\mathrm{R}=0.62, \mathrm{P}<0.05)$.

Table 2 - Descriptive statistics for Regression Analysis 


\begin{tabular}{|c|l|r|r|r|}
\hline \multirow{3}{*}{$\begin{array}{c}\text { Pearson } \\
\text { Correlation }\end{array}$} & Perceived stress & 1.000 & -0.827 & Coping \\
\cline { 2 - 5 } & Hardiness & -0.827 & 1.000 & 0.545 \\
\cline { 2 - 5 } & Coping Strategies & -0.545 & 0.621 & 1.000 \\
\hline \multirow{2}{*}{$\begin{array}{c}\text { Significance } \\
\text { (1-tailed) }\end{array}$} & Perceived stress & & 0.0001 & 0.0001 \\
\cline { 2 - 5 } & Hardiness & 0.0001 & & 0.0001 \\
\cline { 2 - 5 } & $\begin{array}{l}\text { Coping } \\
\text { Strategies }\end{array}$ & 0.0001 & 0.0001 & \\
\hline
\end{tabular}

\section{DISCUSSION}

The aim of the research study was to understand the relationship between Psychological Hardiness, Coping Strategies and Perceived Stress among working adults. Responses from 100 working adults, which included 50 males and 50 females, were the basis for the following findings.

The results of the present study did not support the hypothesis. Both the predictors, i.e Psychological Hardiness and Coping Strategies did not help to predict Perceived stress among working adults. One possible reason could be that working adults who are alienated on the job, who are low in their motivational level and who are not competitive in nature may not be affected by stress in their life and hence being high or low in hardiness may not help them to perceive their level of stress as they least affected by their work culture and work environment. There was a study that who investigated the relationship between stress and the personality variable of hardiness in police officers under stress. In her initial analysis she found that hardiness was related to the symptoms of trauma that were experienced but, after accounting for the stress experienced by the officers, hardiness did not predict the degree of trauma related symptoms [27].

Another possibility is that those working adults who are married and are facing adverse amount of stress on the job as well as experiencing stress in their family life and are unable to have work-life balance, then despite of being high in hardiness will not help them to predict their level of stress, as they might be facing acute stress. Therefore despite of being high in Commitment, Control and Challenge disposition of the Hardiness, they were still affected by the stressors in their life. Hence a negative correlation existed between Psychological Hardiness and Perceived Stress [28].

Also, Coping Strategies did not help to predict how working adults perceived their level of stress. This could be because Coping Strategies could be ineffective in nature and such strategies could just help the individuals to rejuvenate themselves. Another possibility is that in the Perceived Stress Scale, the respondents were asked to rate their feelings and thoughts during last one month, whereas in The Ways of Coping Questionnaire they were asked to think about the stressful situation that they have experienced during one past week. It could be possible that the stressors that the working adults faced during last month were different compared to the stressors they experienced in the past one week and hence coping strategies were ineffective in predicting their perception of stress. A negative correlation existed between Coping Strategies and Perceived Stress.

Lastly, the results could have been inconsistent with the previous findings because, the questionnaires were emailed to the participants, which consisted of multiple-choice options and hence there could have been errors while choosing the right option. The questionnaires were self-report inventories so the participants could have given socially desirable responses. There could be a possibility of a mood bias while responding to the questionnaires.

Individuals who were in sad or negative mood due to workplace stress or who had an argument with a colleague or supervisor before responding to the questionnaire due to could have responded in the manner which reflected their mood and hence scored high on the Perceived Stress scale, despite of being high on 
hardiness. Also, there is a possibility of a sampling bias, because the sample size was small and consisted of only working adults aged 25-35 years and hence the results cannot be generalized.

There existed a strong positive correlation between Hardiness and Coping Strategies which is also consistent with the past studies. Working adults who are high on hardiness make use of adaptive coping strategies like confrontative coping, seeking social support, positive reappraisal, planful problem solving. They tend to use combination of problem focused and emotion focused coping strategy. Those who were low on hardiness gave a high score on escape-avoidance and distancing more often [29].

\section{REFERENCES}

1. Florian V, Mikulincer M, Taubman O. Does hardiness contribute to mental health during a stressful real-life situation? The roles of appraisal and coping. J Personal Soc Psychol 1995;68(4):687-95.

2. Pollock SE. The hardiness characteristic: A motivating factor in adaptation. Adv Nurs Sci 1989;11(2):53-62.

3. Woodard CR. Hardiness and the Concept of Courage. Consult Psychol J Pract Res 2004;56(3):173-85.

4. Low J. The concept of hardiness: A brief but critical commentary. J Adv Nurs 1996;24(3):588-90.

5. Maddi SR. Comments on trends in hardiness research and theorizing. Consult Psychol J Pract Res 1999;51(2):67-71.

6. Lambert VA, Lambert CE, Yamase H. Psychological hardiness, workplace stress and related stress reduction strategies. Nurs Health Sci 2003;5(2):181-4.

7. Judkins S, Reid B, Furlow L. Hardiness training among nurse managers: Building a healthy workplace. J Cont Educ Nurs 2006;37(5):202-7.

8. Carver CS, Scheier MF, Weintraub JK. Assessing coping strategies: a theoretically based approach. J Personal Soc Psychol 1989;56(2):267-83.

9. Lazarus RS. Coping theory and research: past, present, and future. Psychosom Med 1993;55(3):234-47.

10. McElfatrick S, Carson J, Annett J, Cooper C, Holloway F, Kuipers E. Assessing coping skills in mental health nurses: Is an occupation specific measure better than a generic coping skills scale? Personal Individ Diff 2000;28(5):965-76.

11. Fleishman JA, Sherbourne CD, Crystal S, Collins RL, Marshall GN, Kelly M, Bozzette SA, Shapiro MF, Hays RD. Coping, Conflictual Social Interactions, Social Support, and Mood Among HIV-Infected Persons. Am J Commun Psychol 2000;28(4):421-53.

12. Folkman S. Stress: appraisal and coping. Springer New York; 2013.

13. Greenberg JS. Comprehensive stress management. McGraw-Hill Higher Education,; 2011.

14. French JR, Caplan RD, Van Harrison R. The mechanisms of job stress and strain. Chichester [Sussex]; New York: J. Wiley; 1982.

15. Schaufeli WB, Maslach CE, Marek TE. Professional Burnout: recent developments in theory and research. Taylor \& Francis; 1993.

16. Mason JW. A historical view of the stress field. J Hum Stress 1975;1(2):22-36.

17. Aneshensel CS. Social stress: Theory and research. Ann Rev Sociology 1992;18(1):15-38.

18. Turner RJ, Wheaton B, Lloyd DA. The epidemiology of social stress. Amer Sociolog Rev 1995;1:104-25.

19. Hankin BL, Abramson LY. Development of gender differences in depression: An elaborated cognitive vulnerability-transactional stress theory. Psychol Bull 2001;127(6):773-96.

20. Jex SM. Stress and job performance: Theory, research, and implications for managerial practice. Sage Publications Ltd; 1998.

21. Quick JC, Murphy LR, Hurrell Jr JJ. Stress \& well-being at work: Assessments and interventions for occupational mental health. American psychological association; 1992.

22. Payne R, Firth-Cozens J. Stress in health professionals. John Wiley \& Sons; 1987.

23. Quick JC, Tetrick LE. Handbook of occupational health psychology. American Psychological Association; 2003.

24. Kobasa SC, Maddi SR, Kahn S. Hardiness and health: a prospective study. J Personal Soc Psychol 1982;42(1):168-72.

25. Folkman S, Lazarus RS. Manual for the ways of coping questionnaire. Consulting Psychologists Press; 1988.

26. Cohen S, Kamarck T, Mermelstein R. A global measure of perceived stress. J Health Soc Behav 1983;1:38596.

27. Wellbrock KD. Stress, hardiness, social support network orientation, and trauma-related symptoms in police officers. Dissertation Abstracts International: Section B. 2000;61. 
28. Bosma H, Peter R, Siegrist J, Marmot M. Two alternative job stress models and the risk of coronary heart disease. Am J Pub Health 1998;88(1):68-74.

29. Williams PG, Wiebe DJ, Smith TW. Coping processes as mediators of the relationship between hardiness and health. J Behav Med 1992;15(3):237-55.

$* * * * * * * * * * * * * * * * * * * * * * * * * * * * * *$

Acknowledgements - Nil

Source of Funding - Nil

Conflict of Interest - Nil 